\title{
Clinical - Psychological and Psychotherapeutic Intervention
}

\author{
NA Aliyev ${ }^{1 *}$ and ZN Aliyev ${ }^{2}$ \\ ${ }^{1}$ Azerbaijan State Advanced Training Institute for Doctors named by A. Aliyev, department of psychiatry and drug addiction, Baku, Azerbaijan. \\ ${ }^{2}$ Azerbaijan Medical University, department of psychiatry Baku, Azerbaijan.
}

*Corresponding Author: Nadir A. Aliyev, Department of psychiatry and addiction, Azerbaijan State Advanced Training Institute, Baku, Azerbaijan.

Received date: October 04, 2021; Accepted date: December 01, 2021; Published date: January 04, 2022

Citation: NA Aliyev and ZN Aliyev (2022) Clinical - Psychological and Psychotherapeutic Intervention. J. Psychology and Mental Health Care, 6(1): DOI: $10.31579 / 2637-8892 / 147$

Copyright: (C) 2022, Nadir A. Aliyev, This is an open access article distributed under the Creative Commons Attribution License, which permits unrestricted use, distribution, and reproduction in any medium, provided the original work is properly cited.

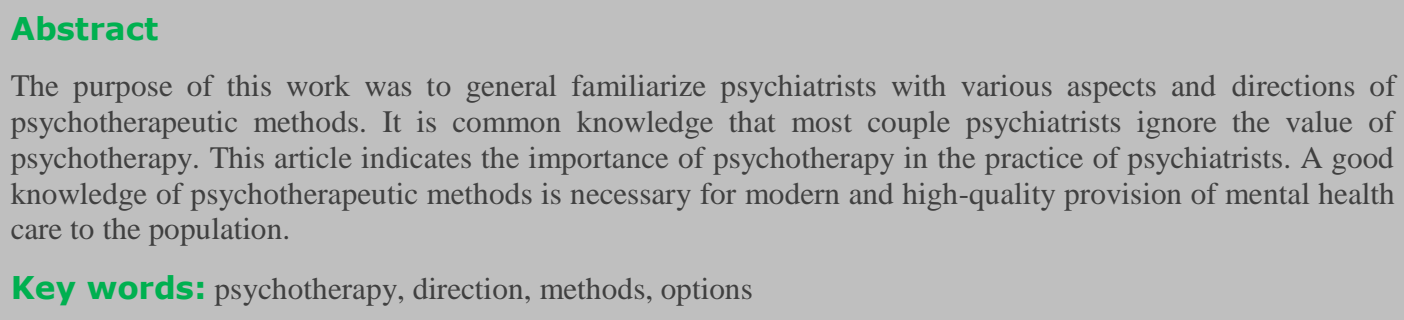

\section{Introduction}

According to the literature, most psychiatrists often do not attach much importance to the use of psychotherapeutic methods in the treatment of their patients. Moreover, some perceive psychotherapy as something practiced by psychologists and other medical practitioners. Psychiatrists generally give preference to biological methods of therapy for patients. Some researchers argue that further efforts are needed to keep this in mind when training psychiatrists in psychotherapeutic psychiatry throughout the life cycle of a career in psychiatry.

Literary data testify to the presence of numerous reports on individual options and methods of psychotherapy $[1,2]$. However, there are very few generalizing research in the field of psychotherapy, its methodology and methods calculated for psychiatrists [3-17].

The purpose of this work was to briefly familiarize psychiatrists with various aspects and directions of psychotherapeutic methods.

Psychotherapeutic intervention - this type of psychotherapeutic effect (type, form), a specific purpose and the appropriate means of influence is characterized by the choice of method. The term psychotherapeutic intervention refers to a specific psychotherapeutic method (eg, explanation, clarification, training, exercise, stimulation, verbalization, interpretation, confrontation, teaching, counseling, etc.), as well as the theoretical orientation of the psychotherapist (above all, the nature of the disorder; understanding the object and issues).

Kilinki - methods of psychological intervention - is a psychological tool chosen by a psychotherapist. They are verbal or non-verbal, mostly focused on either the cognitive, or emotional, or behavioral aspects, and take place in the context of the interaction and interaction between the patient (patients) and the psychotherapist. At the same time, the means of psychological influence not only change the mental processes and state, but also indirectly change the state of the whole organism. Interpersonal relationships, such as conversation, training, or influence and influence, are typical psychological tools.

Despite all the diversity of psychotherapeutic approaches, there are three main directions

Within the psychodynamic approach, personality development and human behavior are viewed as unconscious determinants, while personality disorders and neuroses (F40-F48) are seen as the result of a conflict between the unconscious and the conscious. In this case, the main purpose of psychotherapy is to understand this conflict and, in fact, the unconscious.

Proponents of the behavioral trend focus on behavior. A healthy person is characterized by adaptive behavior. But neurosis or personality change is seen as a non-adaptive behavior formed as a result of improper learning. It can be concluded that the purpose of psychological intervention is to teach or re-learn, ie to replace the form of non-adaptive behavior with adaptive behavior (standard, normative, correct).

Proponents of the humanistic or "experimental" approach view the basic needs of man as the needs of self-realization, self-actualization. Neurosis is the result of the impossibility of self-actualization, the blockade of this need, which is due to the lack of self-awareness and self-acceptance, the lack of integrity and adequacy of the "I-concept". In this case, the main purpose of psychological intervention is to create the conditions for a 
person to experience a new emotional experience, through selfactualization, self-acceptance and integration of personality.

Kilink - the study of the effectiveness of psychological intervention is associated with empirical testing. Scientific evaluation of the effectiveness of psychotherapeutic effects is one of the most important problems. The question of the effectiveness of this or that psychotherapy or psychotherapeutic approach depends not on the report of individual patients, but on the representative selection and certain requirements (precise definition of the method of psychotherapy, homogeneity of the material, random selection, independent experts, psychotherapist and researcher's responsibilities). Division, comparison of direct and distant results of treatment, selection of representative catamnesis, presence of control group, etc.) are confirmed by the results of appropriate scientific studies.

In a number of foreign countries, insurance as a tool of control in the health care system - insurance funds pay only those methods, the effectiveness of which has been empirically proven on the basis of rigorous scientific research. Occupational activity is another feature of clinical-psychological intervention. This means that they must be carried out by professionals trained in the field of clinical psychology and psychotherapy - doctors, psychologists and social workers.

\section{Psychological correction}

Psychological correction consists of psychological influence on certain psychological structures in order to ensure the perfect development of the individual. Because psychotherapy is a treatment practice, according to the law, it can be practiced only by those with higher medical education. The term "psychological correction" is aimed at overcoming this situation: the doctor deals with psychotherapy, and the psychologist deals with psychological correction. However, the relationship between the concepts of "psychotherapy" and "psychological correction" remains open. There are two views on this. The former claim that "psychotherapy" and "psychological correction" are the same.

However, psychological correction is applied not only in medicine (psychoprophylaxis, but also in treatment - psychotherapy and rehabilitation), but also in other human practices, for example, in pedagogy, in the organization of labor. According to the second point of view, the main role of psychological correction is to fulfill its tasks at all stages of psychoprophylaxis (especially in primary and secondary prevention). However, such a strict restriction on the use of psychological correction in medicine is artificial.

\section{Psychological counseling}

There is no single definition of the term psychological counseling. The most common form of psychological counseling is the use of various areas of human activity by a person or group of people (for example, in an enterprise) as a professional seeking solutions to certain difficult problems or problematic situations. For example, school, family, professional, organizational consultations are included here.

There are three main approaches to psychological counseling:

1) problem-oriented consultation: the analysis of the essence of the problem and external causes is focused on the search for their solutions;

2) To prevent problems in the person-centered counseling as a result of the analysis of problems related to the individual, personality and conflict situations and to prevent their recurrence in the future;

3) Consultation aimed at identifying the source of the problem.

Most authors note the similarities between psychotherapy and psychological counseling. The similarity between psychotherapy and psychological counseling is evidenced by the following: 1) both use psychological means of influence; 2) mainly perform development and prevention functions (sometimes, treatment and rehabilitation); 3) increase their effectiveness, aiming for positive changes in the cognitive, emotional and behavioral areas; 4) the scientific basis of both is psychological theory; 5) needs empirical testing (study of effectiveness); 6) carried out in a professional framework.

Nelson-Jones [2] explains the difference between psychotherapy and psychological counseling by saying that while psychotherapy focuses on the individual, psychological counseling focuses on improving one's quality of life by making good use of one's resources. As can be seen, it is difficult to draw the line between psychological counseling and psychotherapy. Defining psychotherapy with patients and psychological counseling as healthy work does not fully meet formal criteria. According to another opinion. Psychotherapy focuses on the individual, while psychological counseling helps people make better use of their resources and improve their quality of life.

\section{General factors of psychotherapy}

From the point of view of what happens to the patient - the general factors of psychotherapy are:

- Orientation of emotional relationships;

- $\quad$ acceptance of patient and psychotherapist self-awareness;

- $\quad$ provide and receive information;

- $\quad$ strengthen the patient's confidence in recovery;

- $\quad$ gain positive experience;

- Relieve emotional distress.

- These factors essentially coincide with the therapeutic effect of psychotherapy and reflect cognitive $(2,3)$, emotional $(1,4,5,6)$ and behavioral (5) processes.

\section{Indications for psychotherapy}

As three main factors (biological, psychological and social) play a role in the etiopathogenesis of various diseases, the effects of each factor on the nature of the correction are required. The indication for psychotherapy is determined by the presence of psychological factors in the etiopathogenesis of the disease, as well as the possible consequences of past or present disease. The most important indication for psychotherapy is the role of psychological factors in the formation and course of the disease.

The outcome of the disease may be associated with clinical, psychological and socio-psychological problems: 1) neurotic symptoms caused by the underlying disease; 2) the person's reaction to the disease (adequate and inadequate - anosognosia or, conversely, hypochondria); 3) severe illness disrupts daily life - the payment and realization of relationships that are important to the person, changes in family and professional activities, narrowing of contacts and interests; decrease in working capacity, activity level and motive components; decline in self-confidence and self-esteem, inadequate formation of stereotypes of emotions and behavior; 4) in need of a corrosive effect, the dynamic transformation of personality traits in the process of chronic disease, ie the formation of personality traits during the course of the disease (high sensitivity, excitement, suspicion, egocentrism).

\section{The main directions of psychotherapy}

According to the theoretical direction of psychotherapy, it is divided into three types: dynamic (psychoanalytic), behavioral and experimental (humanistic). Each of them is characterized by a concept of health and disease, therapeutic purpose, area of intervention, appropriate methods and means of intervention.

\section{Psychodynamic direction of psychotherapy}


This direction of psychotherapy is based on deep psychology psychoanalysis. There are different currents and schools within it. However, what is common to them is the existence of psychotherapeutic methods used to analyze and understand the unconsciousness of mental processes that unite views. Currently psychoanalysis and psychoanalytic (psychoanalytic orientation, deep-psychological orientation). The latter, in turn, is divided into insight - directed and supportive psychoanalytic psychotherapy. Psychoanalysis and psychoanalytic psychotherapy are based on Freud's theoretical ideas of unconsciousness and psychological conflict.

They aim to help patients understand the causes of past internal conflicts, such as childhood symptoms, certain behaviors, and interpersonal interactions. While psychoanalysis and psychoanalytic psychotherapy are based on a general theoretical basis, and psychoanalytic psychotherapy is the development and modification of psychoanalysis, it is expedient to present psychoanalysis in a more serious form in the direction of the psychodynamic model. Psychoanalysis as a complete and complete system has a general psychological theory, a theory of neurosis and a psychoanalytic theory.

\section{Psychological concept}

The founder of psychoanalysis is Freud. The psychological concept, the presentation of personality in psychoanalysis, is an expression of a psychodynamic approach. The term "psychodynamic" refers to a person's mental life, from a dynamic point of view of the psyche, interactions, conflicts and struggles of its components (various psychic phenomena, various aspects of personality) and their impact on human mental life and behavior.

\section{Unconscious mental processes}

Unconscious mental processes play an important role in psychoanalysis. These processes are considered as the main determinant in the development of personality, human behavior as the main driving force of human activity. In general, human mental activity is considered as an expression of unconscious mental processes. The instincts, intentions, primordial, innate, biological tendencies, needs that make up the unconscious threaten thinking, and the field of unconsciousness is suppressed.

Instinct and motives. According to Freud, instinct is not an innate reflex, but a motivating, motivating force of personality. Instincts are the mental expression of stimuli and impulses from orgasm, the mental expression of the state of orgasm (in this sense, biological) or the need that creates this and that. Instinct is the need for thought. The purpose of instinct is to meet orgasm-related needs, arousal, and stimuli in a way that is appropriate for the behavior. Freud believes that internal stimulation, not waking up in connection with the state and needs of the body, is a source of mental energy for human mental activity (including behavioral activity).

Therefore, instinctive awakening is considered as a motivating force, ie motivation is aimed at meeting human needs. Instinct is the mental image of this awakening, which is presented as a desire. Freud's instinct is divided into two groups: 1) life instinct (Eros), aimed at self-preservation, maintenance of vital processes (hunger, thirst, sex); 2) a destructive instinct of death directed inwards, to oneself, or outwards (arrogance, sadism, mosaicism, hatred, suicide). The life energy instinct is called libido, and the death instinct has no special name. Freud believed that the most important of all instincts in the development of personality is sexual instinct. In this regard, the term "libido" is referred to as the energy of sexual instinct. However, it should be noted that "libido" shows the energy of all vital instincts.

The concept of identity
Freud, looking at the problem of the organization of the psyche, personality, created a topographic (level of consciousness) and structural (personality structure) model. Topographic model. According to the topographic model (the earliest), a person's mental life can be divided into three levels: 1) consciousness (what is perceived by man at the present time); 2) in front of consciousness (anything that is not perceived by man at the moment, can be easily perceived in a latent form); 3) unconsciousness (something that is not practically understood by man at the present time; these include instinctive impulses, impressions, memories that threaten the mind and are squeezed into thirst).

\section{Structural models}

It is a later model of personality organization. According to this model, personality has three structures and instances: Id (O), Ego (I) and Super Ego (Higher than Me). Id acts as a source of mental energy in the unconscious, which includes basic instincts, initial needs and impulses. The holiday operates on the principle of enjoyment, ie it is aimed at the immediate elimination of the tension created by the initial desires (biological, from the body), without taking into account any social norms, rules, requirements, prohibitions. The ego (mind, intellect, cognition) directs and controls instincts.

The ego, acting at all levels of consciousness, is the link between the Id and the external world. By analyzing the internal situation and external events, the ego tries to meet the needs of the Id, trying to eliminate the tension (related to the initial need). In this case, the ego acts in accordance with the norms and rules of the external world (for example, the postponement of the payment of needs until the appropriate time). The ego acts on the principle of reality, analyzes the internal and external environment to meet instinctive needs, chooses the most appropriate and safe ways to meet the needs. The Super-Ego is the moral aspect of the personality, the conscience and the ideal "I". Super-Ego operates at all levels of consciousness.

Acting on the principle of moral-ethical Super-Ego controls human behavior (self-control, self-control), prevents internal impulses that do not comply with social norms and standards. Thus, Id makes an urgent attempt to release tension without taking reality into account. Super-Ego prevents the realization of dreams and prevents their realization. Ego reality, taking into account the limitations and requirements of the social environment, seeks to realize the dreams of Id. This becomes a battleground between Id and Super-Ego.

Excessive pressure on the ego causes this excitement. According to Freud, alarm is a function. He warns the ego of the impending danger and helps the individual to choose a safe way in this situation. Freud divides anxiety into three types: 1) objective or real (due to the influence of the external environment); 2) neurotic (associated with the effect of Id); 3) moral (related to the influence of Super-Ego).

\section{The concept of pathology (the concept of neurosis)}

Freud described 9 main types of neurosis. Psychoneurosis arises from a cause of the past, explained in terms of personality and life history. Freud distinguishes three types: hysterical conversion, hysterical fear (phobia) and flash neurosis. The symptoms of this neurosis can be explained as a conflict between Ego and Id. According to Freud, the cause of psychoneurosis is conflict, that is, the Kufic between the unconscious and the tendency to Id.

A neurotic symptom is when a compromise (agreement on mutual concession) is reached between the suppressor and the factor that suppresses the fulfillment of the need. In a neurotic conflict, the SuperEgo forces the Ego to feel guilty (this is a very painful feeling), and even empties in a symbolic and distorted way, which manifests itself as a sign 
of psychoneurosis. All parts of the mental apparatus are involved in the formation of neurotic symptoms.

The causes of topical neurosis are contemporary and are explained in terms of sexual behavior. It occurs as a result of physiological disorders of sexual activity. Freud divides actual neurosis into two forms: neurasthenia as a result of sexual abuse (extremism) and fear neurosis as a result of sexual arousal. Narcissus (self-inflicted, self-inflicted) neurosis is associated with the inability to transmit. The symptoms of character neurosis are, in essence, the secrets of a person's character. Traumatic neurosis is caused by concussion, catastrophe.

Transplant neurosis occurs during psychoanalysis and is associated with the patient's overwhelming interest in psychoanalysis. Organ neuroses are a psychosomatic disease, but the term is rarely used. Childhood neurosis begins in childhood, when classical psychoanalysts believe that adult neurosis is followed by childhood neurosis. Anxiety is the main symptom in the neurosis of fear (anxiety). According to Freud, neurosis is a conflict between consciousness and unconsciousness, which is the result of the suppression of primary, biological needs, above all sexual and aggressive tendencies, under the influence of moral norms, rules, prohibitions.

\section{Psychotherapy}

The legacy of psychoanalytic therapy and the treatment of experience is rightly expressed as follows: 1) to get rid of painful, painful, distressing feelings and impressions, to get rid of them and to affect consciousness through interest in the diversity of human instincts, their various impulses, their expression, transformation, suffocation; 2) to make sure that similar suffocations are mainly sexual - sexual impulses are suffocated: thoughts, feelings and desires, and at the root of the disease is an improper psychosexual development; 3) abnormal psychosexual development is caused by a complex of conflict and trauma in early childhood, especially edip; 4) the belief in resistance to the discovery of this tendency, despite the fact that the person has a conflict, he does not realize it; 5) imagination of the struggle between the psyche and internal biological impulses and instincts, as well as the role of Ego Super - Ego protection; 6) advocating the concept of determinism or causal relationship between events, thought processes or forms of behavior are not coincidental, they are related to events that preceded them, until they are not understood, will manifest and determine the thoughts and feelings of an involuntary person. Given that neurosis is the result of a conflict of consciousness with the unconscious, the main task of psychotherapy in psychoanalysis is to make the unconscious conscious, to perceive the unconscious.

\section{Duties of a psychotherapist - psychoanalyst}

The task of the psychotherapist-psychoanalyst is to reveal the passions, tendencies and conflicts in the unconscious and help to understand them. In order to achieve his goal, a psychoanalyst must analyze a number of mental processes that find expression in the unconscious. These phenomena include free association (the connection between different ideas in the mind), symbolic manifestations of unconsciousness, transfer, and resistance. Free associations or free fantasies - this is the main procedure of psychoanalysis aimed at entering the unconscious.

In this sense, free associations are seen as a fundamental rule of psychoanalysis. Associations are seen as an indicator of unconscious tendencies. Free associations are based on three positions: 1) the desire of ideas to pursue important directions; 2) the patient's need and perception of treatment, direct his associations to significant content (except in cases of resistance); 3) Resistance is minimal during flexibility and maximum concentration.

During the technique of free associations, the patient is asked to weaken the functions of retardation and criticism of the mind, to say even meaningless, stupid, stupid, foolish, bloodless, shameful, guilty, disgusting, shameful, disgraceful, inappropriate, indecent words. The way the symbolic manifestation of immortality closes the way to censorship. But the suppressed tendencies and needs do not lose their energy potential and lead to consciousness.

Some of them "worry" about censorship, as a compromise derivative, without human understanding. They can be identified by psychoanalytic analysis in this way. According to Freud, unconsciously suppressed tendencies, passions, and conflicts manifest themselves symbolically dreams, fantasies, dreams, as various wrong actions (wrong, wrong word, wrong spelling, words, names, dates, etc.).

The content of dreams is divided into explicit, explicit (easily remembered and narrated copies taken from the impressions of recent days) and implicitly unknown types of consciousness. Freud's point is that in his view, dreaming is a censored and distorted representation of tendencies and desires that do not coincide with consciousness and are incompatible with it. The interpretation of the dream consists of the use of associative techniques and the use of symbolic imaginary, imaginary, and imaginative methods of revealing secret thoughts.

\section{Transfer}

Transfer is characterized by the relationship between the psychoanalyst and the patient during psychoanalysis. Transfer shifts his feelings, attitudes, and fantasies about the person who was previously important to him to the psychoanalyst. There are 4 main provisions that define transfer: 1) transfer is a type of objective relationship; 2) the transfer is a repetition of the patient's previous attitude towards the object; 3 ) displacement plays an important role in the transfer reaction; 4) transfer is a backward phenomenon. As a result of the transfer, the patient gives the psychoanalyst an object that was previously important to him. In classical psychoanalysis, the transference projects the feelings and hopes of the parents towards psychoanalyst.

It re-creates some of the feelings that have been important to the patient in the past in relation to the transfer and provides analytical material to the psychoanalyst as a reality. The transfer can be positive or negative, depending on whether the psychoanalytic figure is perceived as benevolent or malicious, biased. During psychotherapy, the psychoanalyst must be emotionally neutral and not present as an individual in order to create the conditions for transfer. Freud wrote: "The doctor must be impenetrable to the patient, he must not show them anything, and what they instruct must reflect them like a mirror."

Contour transfer is a set of unconscious reactions of a psychoanalyst to the patient's identity and, in particular, his transfer. In this sense, contour transfer was initially understood to distort and impede psychoanalysis. But later it became clear that the psychoanalyst's emotional response has a positive role in the transfer of the patient's attitude to one or another aspect of behavior. In the process of psychoanalysis, the psychoanalyst must pay attention to his or her own parts and reactions in order to understand the depths and subtleties of the patient's unconscious area.

Resistance is the prevention of memories, conflicts, manifestations of disease and their understanding, the transition from the unconscious to the conscious. In other words, a person has a conflict, it affects, but it resists their understanding. The psychoanalyst's work with resistance is to estimate certain steps: 1 ) to understand resistance; 2) to demonstrate it to the patient; 3) clarify the motives and forms of resistance; 4) to explain, interpret, interpret the forms of resistance; 5) to follow the unconscious purpose and history of this activity in the patient in the current and past condition of the patient; 6) Careful study of resistance. Analyzes free association, symbolic manifestations of unconsciousness, transfer and resistance in the process of psychotherapy. 
Analyze 4 procedures: confrontation, explanation, clarification and elimination. The patient must distinguish between what to get rid of, what to get rid of, what to get rid of, and the mental phenomenon that is the object of analysis. Clarification is the separation of important, very important, necessary, important impressions from those that are not important. The purpose of interpretation is to understand and comprehend unexplained, misunderstood phenomena. Reveals the essence of events and conflicts based on confrontation and clarification materials. Interpretation is aimed at expanding self-awareness, resulting in the integration of internal processes as a result of understanding.

When interpreting, the psychoanalyst uses his theoretical, practical knowledge, intuition, empathy, as well as his own unconscious. Coping, elimination, (careful research, overcoming) interpretation and investigation are carried out until the resulting resistance materials are understood. Intelligent insight is not enough without research, because there is a tendency to duplicate activities in the usual way. Research consists of complex procedures and processes after insight. The study includes the following elements: 1) repetition of interpretation, especially analysis of transfer resistances;

2) to overcome the isolation of affect and impulses, impressions and memories; 3 ) to expand and deepen the interpretation, to reveal numerous functions, determinants, derivatives of behavioral fragments; 4) not to reconstruct the figure around the patient, which hinders his living future (this includes the reconstruction of certain periods of his past); 6) changes that lead to certain relief (behavior, reactions). The central procedure of analysis is interpretation. Psychoanalysis is a manifestation of unconsciousness.

- Thus, the main categories of psychodynamic psychotherapy can be summarized as follows:

- The concept of pathology is based on the conflict of libido and desires in the unconscious;

- Healing is achieved through the resolution of these conflicts, that is, through the strengthening of the Ego and its victory over the Id;

- Desirable change - to achieve a deep insight (understanding of the distant past, ie intellectual-emotional knowledge)

- $\quad$ is a temporary approach history, directs to the subjective past;

- treatment requires a long time and intensity; the task of the psychotherapist is to understand the content of the psyche of the patient's unconscious, its history, its hidden meaning;

- $\quad$ psychotherapeutic techniques are based on the interpretation of free associations, transfers, resistance errors, dreams;

- The treatment model is medical and authoritarian: doctor - patient or child-parent (ie therapeutic union);

- The psychotherapist takes a passionate and non-directive position, playing the role of interpretation and reflection.

\section{Behavioral direction in psychotherapy}

Based on the psychology of biohaviorism, the principle of teaching is used to change the cognitive, emotional, and behavioral structure. The first condition of methodological behaviorism is philosophical positivity (based on experience, based on facts, reality). According to the proponents of biochemistry, psychology is the science of behavior, because behavior is the only psychological reality that has parameters that can be clearly observed and measured. The basic formula of biochemistry is "stimulus - intermediate variable - reaction" ( $\mathrm{S}-\mathrm{r}-\mathrm{s}-\mathrm{R})$.

Accordingly, the stimulus is recorded as a free variable and the reaction as a dependent variable. Intermediate variables (mediators, mediators) these psychological derivatives express the body's reactions to this or that stimulus. As intermediate variability, attention is considered to imaginations, tendencies, goals, motives, and consciousness. The central problem of biochemistry is individual experience or learning - different skills, abilities, abilities. habit, skill is to gain experience. Learning developed by biochemistry plays a key role in the development of specific methodological approaches to behavioral psychotherapy. Learning is the acquisition of individual experience, abilities and habits as a result of this process.

Behavioral psychotherapy is, in essence, the application of the theory of learning in the clinic. There are three types of learning models: 1) $\mathrm{S}$ (stimulus) learning type; 2) R (behavioral reaction) learning type and 3) social learning. According to the theory of biochemistry, health and disease are the result of what a person learns or does not learn, and personality is a lifelong experience. Neurosis is not considered an independent disease (nosological independence is denied), only its symptoms are evaluated. Neurotic symptoms are considered nonadoptive, ie a behavioral disorder.

According to the behavioral approach, the main goal of psychotherapy is to replace the non-adaptive form of behavior (learning by replacing fear, anxiety with relaxation, etc.) with an adaptive form. The relationship between the patient and the psychotherapist should be of the "teacherstudent" type. The main task of the psychotherapist is to organize the effectiveness of learning. Behavioral psychotherapy is divided into three groups of methods according to 3 types of learning: 1) the direction based on the methodological classical paradigm (systematic desensitization); 2) direction based on methodical operant (instrumental) paradigm (change of numerous psychological parameters, etc.); 3 ) paradigm-based approach to social learning.

\section{Cognitive - behavioral psychotherapy}

General principles of cognitive-behavioral psychotherapy: 1) many symptoms and behavioral problems are the result of deficiencies, shortcomings, deficiencies in teaching, education and upbringing; 2) to help the patient in non-adaptive behavior, the psychotherapist must know the psychosocial development of the patient, see the structure of the field and the violation of various forms of communication; 3) this method should be highly individualized for each patient and family; 4) close connection between behavior and the environment; 5) misconduct is a false (quasi) payment of basic security requirements; 6) the development of a model of behavior consists of both training and psychotherapeutic process; 7) on the one hand, the patient, his thoughts, parts, psychological processes and on the other hand, their results interact with each other; 8) can be considered as a collection of cognitive and cognitive events, processes and structures. The term "cognitive event" refers to automatic thoughts, internal dialogue, and images; 9) cognitive - the main task of behavioral psychotherapy is to help explain how to understand reality; 10) the treatment is of great interest to the patient and the family; 11) Prognosis and treatment outcomes are determined by behavioral improvement parameters.

\section{Experimental (existential humanistic) direction}

Impressions gained in the process of psychotherapy are psychotherapy, which considers the integration of personality through the understanding, acceptance and integration of new experiences, the integrity and unity of the human personality as the main goal. Existentialism has added to humanistic psychology the interest in human existence and its formation. Phenomenology is a descriptive approach to man without initial correction.

Humanistic psychology has developed as an alternative to most psychoanalysis biochemistry. To look at man as a whole, a completely unique person is a fundamental approach of humanistic psychology. The principles of humanistic psychology are expressed as follows: the perception of the nature of the character of human integrity, the role of conscious experience, freedom of will, spontaneity and creative potential of man, the ability to develop. 
Self-actualization - actualization of personal potential. The need for selfactualization is the highest human need, the main motivating factor. But these needs are manifested and determine a person's behavior in order to meet the low needs. Maslow [18] one of the founders of humanistic psychology, developed a model of the hierarchy of needs (the order of subordination of lower ranks to higher ranks): Level 1 physiological needs (food, sleep, sex, etc.); Level 2 - the need for security (the need for security, stability, order, discipline, protection, the absence of fear and anxiety); Level 3 The need for love and belonging (the need for love and community, a certain unity, family, friendship); Level 4 - the need for self-esteem (self-esteem and respect and acceptance by other people); 5th need for self-actualization (development and realization of one's abilities, opportunities, personal potential, improvement of personality).

Experience is a collection of human impressions, any moment that can pass through the mind and take place in the body and with the organism. Consciousness is seen as a symbol of some experiential impressions. The realm of phenomena includes both conscious (ie, symbolized) and unconscious (non-symbolized) impressions.

\section{Organism}

- The body is not just a biological content, in which case the body is a collection of experimental impressions. The organism is an expression of human completeness.

- I - concept - this is self-understanding, how a person represents himself, he is perceived as a part of the person himself. Along with the I-real, there is also the I-ideal.

- Conjugation also determines the possibility of self-realization, ie the perceived "I" corresponds to the actual experience. The perceived "I" as non-congruent does not correspond to the actual practice.

- Within the humanistic approach, the main human need is to actualize oneself. In this case, neuroses (F40-48) are considered as a result of the impossibility of self-actualization as a result of alienation from themselves and the environment.

\section{Psychotherapy}

The psychotherapist realizes 3 variables of the psychotherapy process in sequence during the course of his work with the patient. The first is empathy. Empathy is the psychotherapist's ability to be in the patient's place, to feel his inner world, to understand his thoughts as the patient understands. The second is to have an unconditionally positive attitude towards the patient or an unconditionally positive attitude. Third - the special congruence or credibility of the psychotherapist, having the same strength, complete compliance. All three of these parameters are included in the literature, the "Rogers Triad", and are the result of a clear view of personality and the emergence of distortions.

\section{Existential psychotherapy}

It is based on phenomenological and existentialist philosophy and psychology. The central concept of the theory - existence (lat. Existentia - existence, existence; existence; living, being, life, vitality, life; existence) is like an unbroken whole object and subject. The main existential manifestations of man are care, fear, determination, conscience, sin, love. All manifestations are determined by death - man perceives his existence in borderline and extreme (struggle, suffering, death) situations. Man acquires his freedom by understanding his own existence.

Kraus characterizes the direction of existential-humanistic psychotherapy in the following categories:

- the concept of pathology (loss of human abilities, fragmentation of the "I", incompatibility with one's own knowledge is perceived as the essence of an existal based on despair);
- health (related to the realization of human potential - the development of "I", the achievement of originality, impartiality);

- Desirable, any changes (impressions, perceptions, expressing one's feelings or love in the present moment);

- $\quad$ temporal approach (out of date, phenomenological focus);

- $\quad$ treatment (short-term and intensive);

- The task of the psychotherapist (to create an atmosphere of communication aimed at mutual understanding, to help selfexpression - from somstik to spirit, spirituality);

- basic psychotherapeutic method (meeting as a full participant in dialogue, practice, play, staging);

- treatment model (existential: dialogue of equal people or "GreatGreat" ie human union);

- the patient's attitude to treatment (considers it realistic and imagines t very important and significant);

- the position of the psychotherapist (acts as an interacting and accepting, reciprocal solution and reciprocal).

\section{Family psychotherapy}

Family psychotherapy, as a special type of psychotherapy, focuses on the coordination of interpersonal relationships in order to eliminate emotional disorders in the family, especially in patients with emotional disorders. In other words, it is the patient's psychotherapy in the family and with the help of the family.

The main objectives of the various models of family psychotherapy are:

- to develop a number of ideas (goals, intentions, opinions, assumptions) in the family about the problems raised;

- to transform the views of family members on the problem from an individual to a systematic approach;

- modify the boundary between subsystems to the ability to penetrate channels;

- Develop a model for alternative solutions to problems, either directly or indirectly;

- $\quad$ reduce the emotional involvement of family members in the symptomatic symptoms of one member of the family;

- correlation of those who do not fit into different forms of hierarchy;

- To stop and break the dental functional stereotypes taken from the parent's family, to reveal the important work of "unfinished work", to reveal family secrets, to improve the communication style between family members.

\section{Basic positions of the system approach}

The family system is open, in which family members interact both with themselves and with other systems (school, industry). The family ("feedback") is a constantly evolving system as a result of interaction with the external environment (biological and social). External forces can have a positive or negative effect on the family. Thus, the family system, on the one hand, maintains the established relationships, on the other hand, tries to develop it and operate at a higher level. Harmonic family members respond quickly and adequately to changes in internal and external circumstances. A healthy family is not based on the dominance of parents over children, their strength ensures the safety of the latter. Here, family rules are clearly the benchmark for the positive development of each member of the family. The following characteristics of a harmonious family are listed.

- All family members keep in touch with each other. The opinion of each family member is taken into account during the dispute. Healthy family intimacy is a manifestation of love and at the same time negative emotions.

- There is a division of duties and responsibilities among family members. 
- Family members support each other, are able to share and fulfill the responsibilities of another family member when the situation changes (business trip, illness).

- $\quad$ Every member of the family believes in himself, values himself adequately, trusts other family members.

- Teach respect for other people, instill an adequate approach to their tastes and preferences.

- $\quad$ Family members have common values and know their rights.

- There is a family tradition, they know their ancestors (ancestors) and roots.

- Basic positions of the system approach

- Coalition among family members is dynamic and changeable. In the absence of jealousy and despair, family members are allowed to change their roles within the family, which is a vital requirement in determining the personal and social boundaries.

- A sense of humor is valued, a positive attitude to life is nurtured.

- Focus on spiritual exercise.

- Take time to have fun.

- Joint food intake is encouraged, encouraged, encouraged.

- Altruism is encouraged (forgetting one's own interests and taking care of others, being ready to help others free of charge).

- Family members create conditions for their personal development.

- Family members are not ashamed to consult a specialist when there is a crisis or problem.

The disharmonious family system works rigidly to maintain the usual stereotypes without changing the external environment. As a result, the actual needs, demands and needs of the most "weakest" in the family (mostly children) are blocked, and any disease (mental illness) develops in it. Being a "carrier sign", he keeps old activities and habits in the family. Open discussion of topics leads to a violation of family rules. If the family is seen as a self-regulating system, if the sign acts as a mechanism that regulates it, then the disappearance of the sign becomes a system in which the family is temporarily unregulated.

Family psychotherapy is usually divided into 4 stages: 1) diagnostic (family diagnosis); 2) to resolve the family conflict; 3) reconstruction; 4) retainer (supportive). It is important to note that the phased conduct of family psychotherapy is determined by the specific dysfunctional family context and direction of psychotherapy.

\section{Family diagnosis}

Family diagnosis is the clinical basis of family psychotherapy, requiring the clinician to have a systematic approach and the ability to collect anamnestic data. The following scheme can help to make a family diagnosis:

- What recent events have affected the family?

- How did family relationships differ before, during, and before the problem arose?

- Why does the family apply now?

- Was the family dysfunction acute (crisis) or chronic? Getting information about the history of the family allows you to get into the myths and secrets of the family.

- How do family members reflect on the family system when they agree to see a psychotherapist? (Initiator of the appeal, responsible member of the family or the most guilty of the problem).

- Is the presented problem or symptomatic behavior related to a violation of the family's internal system?

- "Identified patient" - a family member with a psychological problem whose behavior deviates and is the reason for consulting a psychotherapist. An "identified patient" or "symptom carrier" occurs when the family is stable or at certain stages of the life cycle when the conflict is resolved in an inadequate manner.
- Detection of communication disorders in the family (internal and external family).

- Identify distortions in emotional relationships between parents.

- Use differential styles to cope with stress (eg, inadequate aggression or avoidance of illness).

\section{The concept of group psychotherapy}

Group and individual psychotherapy are the two main types of psychotherapy. The main emphasis of individual psychotherapy is on the historical (genetic) aspect of the person, group psychotherapy affects the most interpersonal aspect. Group psychotherapy mainly consists of three parts of self-thinking: self-awareness (cognitive aspect), self-attitude (emotional aspect) and self-regulation (behavioral aspect).

The therapeutic mechanisms of group therapy are mainly divided into: 1) information; 2) to inspire hope; 3) universality of suffering; 4) altruism (forgetting one's own interests and taking care of others, not being ready to help others free of charge); 5) re-coordination of the initial family group; 6) development of interpersonal communication tonic; 7) imitation behavior; 8) interpersonal effects; 9) group solidarity; 10) catharsis.

The main methods of group psychotherapy are traditionally: group discussion, psychodrama, psychogymnastics, projection image and music therapy. All group psychotherapies are conventionally divided into: basic and auxiliary, verbal and non-verbal. Group psychotherapy is based on discussion, while others are helpful. In this case, the whole group of psychotherapy performs two main tasks: psychodiagnostics and psychotherapy in the true sense of the word. It is divided into verbal and non-verbal communication according to the type and nature of the received material. The verbal method refers to group discussion and psychodrama.

Nonverbal cues include psychogymnastics, projection imaging, and music therapy. The term "verbal" is sometimes equated with the terms "rational", "cognition", and "non-verbal", "emotional" and "experience" (in the sense of experience). Group discussion is the basis of psychotherapy. Along with this term, free discussion, spontaneous discussion, discussion without a certain structure, etc. understanders are also used. The subject of group discussion is the patient's biography, specific topics and interpersonal interactions in the group.

The classic psychodrama procedure involves the following participants: the protagonist (this is the patient), the therapist (director, conductor), the therapist (assistant therapist), the scene (living space, the place where the psychodrama takes place). Psychodrama consists of three phases: initial or preparatory ("digging" phase), real psychodramatic actions and discussion.

The basis of psychogymnastics is motor expression and belongs to the non-verbal group psychotherapy. Psychogymnastics involves the expression of emotional feelings through actions, facial expressions, and pantomime. Psychogymnastics usually consists of three stages: preparatory, pantomime and final. During the preparation phase, reducing tension within the group, eliminating fears and restrictions, increasing attention to their actions, shortening the emotional distance with group members, etc. In the pantomime stage, the topic offered to patients is played non-verbally. The last stage of psychogymnastics leads to the elimination of tension.

\section{Projective picture}

During the projective picture, each patient is given a white sheet and a colored pencil and asked to draw a picture on the subject. The topics of sidewalks mainly cover three areas: 1) the patient's past, present and future (how I am, how I would like to be, how I look around, among people, in my family, at work, my favorite and disliked memories); 2) concepts that reflect certain values and events (love, hate, illness, fear, 
health, addiction, responsibility); 3) attitude to the group (I through the eyes of the group, my position, place, role in the group). It usually takes 30 minutes to take a picture. The group then discusses the picture taken by each patient.

Music therapy is the use of music as a means of healing. Music therapy is divided into 4 aspects: 1) emotional activation during verbal psychotherapy; 2) development of interpersonal skills - communicative functions and abilities; 3) regulation of psychovegetative processes; 4) development of aesthetic needs. Music therapy is mainly carried out in two forms: active (improvised with your own voice or played on a musical instrument) and receptive (passive) - listening to music.

In general, the objectives of group psychotherapy are: 1) to treat group members, discuss their emotional reactions and suggested topics; 2) to create mutual trust, good relations, safe conditions between group members, etc. 3) to develop and maintain valuable group norms.

Verbal methods, which are the main means, are conventionally divided into several categories. 1) the structural course of the issue; 2) information collection; 3) interpretation; 4) to convince; 5) provide information; 6) setting certain goals.

The psychotherapeutic group is divided into open and closed. There is no permanent composition of the open group: if one of the participants leaves the group, another patient replaces him. If it is closed, no other patient is admitted to the place of abandonment, ie the composition of the group remains stable. Group therapy is used in the complex treatment of neuroses, addiction to psychoactive substances, chronic somatic patients.

The distance between people is divided into several places.

- Distance 0-45 cm - "intimate", mutual relationships are found in close people: husband and wife, mother and child, close friends and relatives.

- Distance 45-120 cm, called "personal distance". It is characterized as partner communication, ie having the same social status and combined with common activities.

- Distance 120-400 cm - social distance - this is done in formal, formal communication between two people. The patient feels 200 $\mathrm{cm}$ comfortable at the meeting with the doctor. At this distance, the patient quickly becomes irritable, enters the doctor's "living space" without holding hands, bored, rude, impolite, disrespectful, shameless, disrespectful. These individuals are usually infantile, dependent, and in need of emotional support.

- When the distance is 4-7.5 m, it is called "open, in public, distance". It is characterized by formal communication of several people. The issue is meeting at this distance.

- Distance 120-400 cm - social distance - this is done in formal, formal communication between two people. The patient feels 200 $\mathrm{cm}$ comfortable at the meeting with the doctor. When the patient quickly shortens this distance, enters the doctor's "living space" without giving up, bored, rude, impolite, disrespectful, shameless, disrespectful. This person usually has infantile, dependent, emotional support needs.

- When the distance is 4-7.5 m, it is called "open, in public, distance". It is characterized by formal communication of several people. The issue is meeting at this distance.

- The position of interlocutors is divided into several main types.

- "Face to face", position against each other. There is an element of confrontation in this position. Such positions are found during conflicts and tensions.

- Side-by-side, "side-by-side" position - is a position of cooperation, a sign of absence of tension and hostility between partners.

- Communication through the table is practically always power, authority, authority, power, to show, to express, to express. This type of interaction excludes reliability and complicates psychological contact. Therefore, when receiving a patient in the doctor's office, the chair should be placed on the side of the table, not facing the table where the patient is sitting.

During verbal contact with the patient, if the doctor pulls or bends over while sitting in a chair or armchair during the conversation, the patient will think that his speech is boring for the interlocutor or he does not agree with him. In response to the patient's words, the doctor, on the other hand, will believe the doctor's interest and sincerity if he leans slightly toward the patient and lowers his head to his right shoulder when he hears the patient.

\section{Pose}

The pose is very important to assess the condition of the interlocutor. The pose can be natural or unnatural. Pose is a sign of natural - free, simple psychological comfort, lack of tension, intention to communicate. Conversely, if the pose is unnatural - unusual, strange, meaningless - it indicates a lack of intention to communicate, which is evidence of tension and dental comfort. Unnatural, strange posture is characteristic of patients with schizophrenia. The pose is symmetrical and asymmetrical. The symmetrical pose eliminates the difference between the individual, the difference in characteristics.

For example, uniforms make people look a bit like each other. Symmetrical pose - a formal touch, a formal interaction consisting of a certain rule (order). According to the symmetrical pose, people are closed, have high control, interact with caution, do not trust anyone, do not trust, and are skeptical of everything. With a person with an asymmetrical posture, on the contrary, they are open to contact and ready to cooperate. The pose is both open and closed. Closed pose is characterized by avoidance of communication with others.

Distinguishing features of the closed pose are crossed arms on the chest ("Napoleon pose"), crossed legs (crosses the legs over the legs); hides hands in pockets or behind; body and head turn away from the partner; They look, but they do not look into the eyes of the interlocutor. A closed pose avoids contact. An open pose indicates contact, an interpersonal effect.

The open pose is characterized by the opposite signs compared to the closed pose: the torso and head of the body turn towards the interlocutor, the face looks diffuse, and so on. The doctor's professional contact with the patient should be natural, asymmetrical, open. This in turn allows you to have contact with the patient, creating good conditions for interaction without creating tension or mistrust. These are especially important during the initial psychological contact with the patient.

\section{Gesture}

The gesture is the movement of the hands in the presence of the shoulder and head. All gestures are divided into two groups: communicative (communicative) and expressive (meaningful, effective). The communicative gesture has a definite meaning for the environment. They are used instead of words in communication, helping to communicate. We ask, "How are you?" I don't know the question, instead of the word we bend our shoulders, raise our eyebrows. Instead of saying "yes", we answer with a nod. There are appropriate gestures between certain professional groups (athletes, cars). In addition to corporate gestures, gestures are divided into national and international gestures. National gestures refer to those adopted in any country. Active, excessive gesture is observed during arousal and manic arousal. In a depressed state, static monotony, monotony, boredom, boring posture, very few gestures, sadness, grief, sadness prevail.

Facial expressions are coordinated movements of facial muscles that reflect emotions, moods and feelings. The most informative way to give 
these or other impressions is the facial expressions of the lower part of the face: the line of the mouth, the wings of the nose, the corners of the lips on the wings of the nose, the nasal lip to the chin. The most informative part of the human face is the mouth. When the mood is good and the vital tone is high, the mouth line is straight. During depression, sadness or fatigue, the corner of the lip sags down. Expressive people with curved noses and lips are considered passionate, passionate, enthusiastic, passionate, enthusiastic. The expression of the forehead muscles is also attractive. There may be horizontal and vertical wrinkles on the forehead. Horizontal wrinkles are a sign of excitement and surprise. Vertical wrinkles show grief, sadness and anger.

\section{Overview (eye contact)}

Non-verbal communication is one of the most important elements of a relationship. It allows you to establish psychological contact with the interlocutor by looking into the eyes. Some people avoid looking into the eyes of others and do not fix their gaze on the face of the interlocutor. "Running look" is usually dental comfort during communication shows ambivalence towards others. The optimal scan lasts 3 seconds. At the same time, it does not irritate the partner, allowing him to determine the psychological contact. If the look lasts for $3-10$ seconds, it is called attentive, erect, blunt, and creates tension and discomfort in the interlocutor. If the look lasts more than 10 seconds, it is either an expression of a call for confrontation or aggression. In other cases, mutual sexual provocation between a man and a woman is an indication of provocation.

People who are calm, self-respecting, and satisfied with themselves and their life situation are more likely to look into the eyes of their interlocutor in interpersonal communication than people who are emotionally unstable. In verbal communication, the speaker looks at the listener more than the listener, and vice versa. There is a connection between the frequency of views and punishment. Parents are more likely to punish children who avoid looking them in the eye, and in some cases, children who look after their parents more often and for longer periods of time are also punished. Leaders tend to punish those who run away from their subordinates more often. The frequency of views is related to the sense of control of managers and adults.

The concept of catharsis was still introduced by Aristotle. He affirmed that empathy (catharsis) is achieved by sharing one's pain and showing compassion. Catharsis is considered the central psychotherapeutic mechanism of psychoanalysis. Listening carefully to the patient's complaints during the active phase of orientation is an element of the psychotherapeutic effect familiar to every physician.

\section{Conclusion}

Thus, this article indicates the importance of psychotherapy in the practice of psychiatrists. A good knowledge of psychotherapeutic methods is necessary for modern and high-quality provision of mental health care to the population.

\section{Conflict of Interest Statement}

The authors declare that the research was conducted in the absence of any commercial or financial relationships that could be construed as a potential conflict of interest.

\section{References}

1. Denman C (2011) The place of psychotherapy in modern psychiatric practice. Advances in Psychiatric Treatment, 17: 243-9. 2011.

2. Johnston J (2017) Learning from the Cradle to the Grave: The Psychotherapeutic Development of Doctors from Beginning to End of a Career in Medicine and Psychiatry (Occasional Paper OP102). Royal College of Psychiatrists. Johnston, 2017.

3. William Burbridge-James \& Maciej Iwanowicz. (2018) Psychotherapeutic interventions and contemporary developments: common and specific factors. B J Psych Advances, vol. 24, 54-65.

4. Barlow DH. (2004) Psychological treatments. American Psychologist, 59: 869-78.

5. Bateman AW, Fonagy P. (2008) 8-Year follow-up of patients treated for borderline personality disorder: mentalization-based treatment versus treatment as usual. American Journal of Psychiatry, 165: 631-8.

6. Bateman A, Fonagy P. (2010) Mentalization based treatment for borderline personality disorder: World Psychiatry, 9(1), 11-5.

7. Kazdin AE, Blase SL (2011) Rebooting psychotherapy research and practice to reduce the burden of mental illness. Perspect Psychol Sci, 6: 21-37.

8. Arean PA, Kraemer HC (2013) High-Quality Psychotherapy Research: From Conception to Piloting the National Trials. Oxford, Oxford University Press.

9. Freud S. (2014) Remembering repeating and working-through: further recommendations on the technique of psycho-analysis II. InThe Standard Edition of the Complete Psychological Works of Sigmund Freud, vol.12: 147-56. Hogarth Press.

10. Laska KM, Gurman AS, Wampold BE. (2014) Expanding the lens of evidence-based practice in psychotherapy: a common factors perspective. Psychotherapy: Theory, Research, Practice, Training, 51: 467-81.

11. Brand RM, Palmer FT. (2015) A service evaluation of an acceptance and commitment therapy group in an early intervention in psychosis service. Clinical Psychology Forum, 267: 21-5.

12. Montgomery-Graham S. (2016) DBT and schema therapy for borderline personality disorder: mentalization as a common factor. Journal of Contemporary Psychotherapy, 46: 53-60.

13. Fava GA, Cosci F, Sonino N (2017) Current psychosomatic practice. Psychother Psychosom, 86:13-30.

14. Bos FM, Snippe E, de Vos S, Hartmann JA, Simons CJP, van der Krieke L, de Jonge P, Wichers M (2017) Can we jump from crosssection- al to dynamic interpretations of networks? Psychother Psychosom, 86:175-177.

15. Guidi J, Tomba E, Cosci F, Park SK, Fava GA (2017) The role of staging in planning psychotherapeutic interventions in depression. $J$ Clin Psy- chiatry, 78:456-463.

16. Mulder R, Murray G, Rucklidge J (2017) Common versus specific factors in psychotherapy: opening the black box. Lancet Psychiatry: 953-962.

17. Sanchez-Moreno J, Bonnin CM, González- Pinto A, Amann BL, Solé B, et al (2018) CIBERSAM Functional Remediation Group: Factors associated with poor functional outcome in bipolar disorder: sociodemographic, clinical, and neurocognitive vari- ables. Acta Psychiatr Scand.

18. Maslow, A. H. Motivation and personality, 1954, Harpers. 